\title{
Desafios da mobilidade urbana no Brasil e o uso da bicicleta como uma alternativa de transporte em Campos dos Goytacazes/RJ
}

\begin{abstract}
Resumo: 0 crescimento em muitas cidades brasileiras de forma acelerada e desordenada trouxe consequências controversas, que vão desde os serviços de infraestrutura básica ao direito de ir e vir. Os interesses políticos, econômicos e até sociais, em sua maioria individualizados, vão ganhando espaço no debate das políticas públicas e restringindo a concepção de um direito coletivo, de um direito à cidade como um lugar de encontro e trocas. 0 aumento massivo de uso de veículos motorizados individuais ganha destaque no cenário da mobilidade urbana, em detrimento do uso da bicicleta, uma das formas de transporte mais baratas e não poluentes. 0 sistema cicloviário, na maioria das cidades do País, ainda é insatisfatório, devido à falta de infraestrutura adequada. Portanto, este artigo objetiva contextualizar o uso da bicicleta na mobilidade urbana no Brasil, destacando a ausência de políticas públicas efetivas de mobilidade urbana, sobretudo na cidade de Campos dos Goytacazes/RJ, em que o Plano de Mobilidade Urbana ainda se encontra em formulação.
\end{abstract}

Palavras-Chave: Mobilidade urbana. Bicicleta. Políticas Públicas.

\begin{abstract}
The accelerated and disorderly growth in many Brazilian cities has led to controversial consequences, ranging from basic infrastructure services to the right to come and go. Political, economic, and even social interests, mostly individualized, are finding their way into the public policy debate and limiting the conception of a collective right, a right to the city as a place for meeting and exchange. The large-scale increase in the use of individual motor vehicles is being given attention in the urban mobility scenario, particularly at the expense of cycling, one of the cheapest and most non-polluting means of transport. In most of the Brazilian cities, the bicycle path system is still unsatisfactory owing to the lack of adequate infrastructure. Hence, the purpose of this paper is to contextualize the use of bicycles in urban mobility in Brazil, emphasizing the lack of effective public policies on urban mobility, particularly in the city of Campos dos Goytacazes, Rio de Janeiro State, Brazil, where the Urban Mobility Plan is still under formulation.
\end{abstract}

Keywords: Urban mobility. Bicycle. Public policies.

\footnotetext{
Elias Andretti Dantas do Vale

Arquiteto e urbanista graduado pelo IFF - Centro, mestrando no Programa de Pós-graduação em Desenvolvimento Regional, Ambiente e Políticas Públicas - PPGDAP/UFF Campos, bolsista CAPES. E-mail: dovaleelias@gmail.com
}

\section{Érica Tavares}

Professora adjunta do Departamento de Ciências Sociais (COC) e do Programa de Pós-graduação em Desenvolvimento Regional, Ambiente e Políticas Públicas - PPGDAP/UFF Campos.

E-mail: ericatavr@gmail.com 


\section{Direito à cidade, mobilidade urbana e as potencialidades do uso da bicicleta}

Uma das dimensões fundamentais da apropriação do espaço na cidade está ligada às condições de mobilidade urbana. 0 ir e vir de diferentes lugares expressa as possibilidades de acesso aos diferentes recursos, bens, serviços, equipamentos urbanos, assim como às oportunidades de trabalho, educação e mesmo à moradia. Se pensarmos que o direito à cidade envolve a transformação da cidade e a construção coletiva de outra sociedade, a possibilidade de circular na cidade pode ser tomada como uma dimensão fundamental para esta (re)apropriação e transformação da cidade.

A concepção do direito à cidade relaciona-se com a ideia de uma construção coletiva dela, a construção de outra sociedade, da cidade como espaço da troca, do encontro, da vivência. Harvey (2014, p. 28) aponta que o direito é mais coletivo do que individual, visto que reconstituir a cidade depende indubitavelmente do exercício de um poder coletivo sobre o processo de urbanização. As diferentes relações nas cidades são importantes para as atrações que nela existem, tal como Lefebvre (1999, p. 109) aborda:

A cidade atrai para si tudo o que nasce, da natureza e do trabalho, noutros lugares: frutos e objetos, produtos e produtores, obras e criações, atividades e situações. 0 que ela cria? Nada. Ela centraliza as criações. E, no entanto, ela cria tudo. Nada existe sem troca, sem aproximação, sem proximidade, isto é, sem relações. Ela cria uma situação, a situação urbana, onde as coisas diferentes advêm umas das outras e não existem separadamente, mas segundo as diferenças (LEFEBVRE, 1999, p. 109).
As migrações do campo para a cidade, desde a metade do século XX no Brasil, fizeram com que as urbes fossem crescendo, e os centros urbanos fossem se tornando cada vez mais densos e movimentados. 0 crescimento acelerado de muitas cidades, de forma desorganizada, contribuiu para o aumento de problemas sociais, restringindo os direitos das pessoas à cidade.

0 município analisado neste estudo, Campos dos Goytacazes, no estado do Rio de Janeiro, também foi uma expressão desse processo, sendo possível observar que a consolidação do espaço urbano se deu mediante uma série de contradições sociais e econômicas, que se traduziram na apropriação do espaço. Em meio ao declínio de atividades econômicas de base agropecuária, houve uma expressiva saída do campo para a cidade na segunda metade do século XX, gerando desemprego e aumento da pobreza urbana. Segundo Cruz (2003), vários bairros urbanos foram formados nesse contexto, que "gerou um contingente de milhares de boias-frias, expulsos do campo para a cidade, vivendo em condições precárias de vida e de renda" (CRUZ, 2003, p. 297). A localização dos grupos mais pobres em áreas periféricas e segregadas da cidade apresentou, e ainda apresenta, uma estreita relação com as condições de mobilidade urbana e acesso aos meios de transporte.

A força de agentes públicos e privados na ocupação do espaço e nos deslocamentos, tanto em Campos quanto em várias cidades brasileiras, evidencia que os interesses políticos, econômicos e sociais nas cidades, progressivamente, vêm se tornando mais em interesses privados do que coletivos, desacordando com o que Harvey (2014) abordou, que o direito era mais grupal do que individual.

\section{Os seus sonhos não podem esperar}


A ocupação do espaço urbano junto com as lutas dos movimentos sociais é relevante para se conquistar 0 direito coletivo cada vez mais ausente nas cidades. As manifestações/revoltas em favor da mobilidade urbana no Brasil, em junho de 2013, quando a população lutava por uma diminuição na tarifa do transporte público, ocupando espaços públicos, elucidam uma das formas de se exercer o direito à cidade, o direito de manifestação, um direito que não se pode comprar nem vender.

Oliveira Júnior (2011) traz uma discussão muito relevante sobre o reconhecimento da mobilidade urbana como um direito social e também com um status constitucional. Oliveira Júnior (2011, p. 67) debate sobre o art. 30, inc. V, da Constituição Federal, que diz que é de competência dos municípios organizar e prestar serviços públicos de interesse local, incluindo o transporte coletivo. Ademais, 0 art. 37, inc. XXI expõe a possibilidade de que a prestação dos serviços públicos seja realizada por iniciativa privada, por intermédio da obrigatoriedade de licitação. Cabe aqui ressaltar os questionamentos que Oliveira Júnior (2011, p. 67) discorre mediante a legislação:

Primeiramente, nesta lógica constitucional de prioridade à regulação e não à prestação de serviço público pelo poder público, como assegurar que a mobilidade urbana por transporte público seja acessível a todos e não apenas àqueles que possam pagar pela tarifa?

Segundo, como garantir que os deslocamentos não motorizados serão devidamente assegurados se as nossas cidades foram construídas sem se preocupar com as pessoas, mas, sim, com a circulação de automóveis privados, gerando assim um enorme passivo de infraestrutura urbana adequada aos deslocamentos a pé e por bicicleta e acessiveis às pessoas com deficiência? (OLIVEIRA JÚNIOR, 2011, p.67).

Para Oliveira Júnior (2011, p. 73-74), a mobilidade urbana deveria ser elevada a um status de direito social constitucional que, a médio e longo prazo, propiciaria a repactuação social a favor de um direito coletivo - direito de comunidade. 0 objetivo desta ação seria melhorar as condições do sistema urbano nas cidades, além do fortalecimento da coesão social em conjunto com a maior solidariedade entre os membros da comunidade. Embora o direito de ir e vir seja pensado, a princípio, na esfera individual, na abordagem do direito à cidade que a pensa enquanto obra e construção coletiva, ele pode ser recolocado como um direito coletivo, pois remete à ampliação da acessibilidade a lugares, bens, recursos e oportunidades por parte de todos - aspecto fundamental para se pensar em outra cidade transformada.
O uso da bicicleta, apesar de também ser um transporte individual, pode proporcionar um acesso mais equitativo aos espaços urbanos. Boa parte dos investimentos, no que tange à mobilidade urbana, privilegia 0 acesso dos motorizados individuais às ruas e avenidas, sendo o uso da bicicleta colocado em um plano mais distante. 0 transporte ativo - entendido como pedalar e andar (ANDRADE et al., 2016, p. 12) - é uma das formas de transporte mais baratas, 0 que possibilita à maior parte da população utilizá-lo, apesar de seu uso envolver outras dimensões subjetivas. Portanto, o uso da bicicleta pode contribuir para um espaço mais acessível nas cidades.

A maioria das políticas públicas no Brasil substancializa no espaço uma desigualdade social. Esta torna-se mais efetiva com as políticas de mobilidade urbana, que favorecem o uso do transporte motorizado individual, leia-se, de maior padrão de renda. Para Aragão e Souza (2016, p. 82), ao se criarem políticas que priorizem o transporte não motorizado, seja a pé, seja de bicicleta, tende-se a criar modelos de cidades mais justas. Além disso, seu padrão se eleva, o trânsito se torna mais eficiente e há uma menor emissão de gases poluentes na atmosfera.

Em muitas cidades brasileiras, o automóvel, transporte motorizado individual, vem ganhando cada vez mais espaço nas ruas. Lefebvre (1991, p. 112) acredita que o carro é símbolo de posição social e de prestígio. Nele, tudo é sonho e simbolismo: de conforto, de poder, de prestígio, de velocidade. Ainda segundo Lefebvre (1991, p. 111):

0 veículo automóvel não se reduz a um objeto material dotado de uma certa tecnicidade, meio e lugar socioeconômico, portador de exigências e de pressões. 0 automóvel dá lugar às hierarquias: a hierarquia perceptível e sensível (tamanho, potência, preço) e se desdobra numa hierarquia mais complexa e mais sutil, a das performances (LEFEBVRE, 1991, p. 111).

0 excessivo uso de automóveis nas cidades desencadeia uma série de problemas, que poderiam ser amenizados com investimentos e maior atenção para os diferentes modais que compõem a rede de transportes urbanos. Uma malha de transportes públicos eficiente contribui para a redução de trânsitos e congestionamentos intensos. 0 ônibus é a forma de transporte público mais comum no mundo (VASCONCELLOS, 2012, p. 20).

Diversas cidades ao longo do mundo têm buscado soluções que considerem o modelo rodoviário de 
transporte ultrapassado, pois a mobilidade encontra-se cada vez mais restringida, por razão desta prioridade dos motorizados individuais. Com isso, projetos que incentivam a redução dos automóveis nas ruas, a integração do sistema de transporte público e a ampliação da rede cicloviária têm ganhado destaque no cenário de planejamento urbano. Para Trigueiro (2016, p. 8):

Interligar os diferentes modais de transporte emprestando organicidade ao planejamento é outro traço comum a essas cidades que, sem exceção, abriram caminho para as bicicletas. A "magrela" jamais será a solução para todos os problemas de mobilidade, mas sem dúvida alguma, a melhoria da mobilidade passa por ela (TRIGUEIRO, 2016, p. 8).

A bicicleta, um dos meios de transporte ativo, possui grandes vantagens, por ser de baixo custo de aquisição e manutenção, ser de fácil utilização, maior disponibilidade de estacionamento, além de proporcionar benefícios à saúde, especialmente, ao meio ambiente. São muitas as prerrogativas associadas a ela, portanto, 0 modal tem sido considerado um meio de transporte sustentável, barato e acessível para toda a população, contribuindo para deslocamentos mais eficazes no meio urbano.

0 transporte cicloviário desfruta de diversas características positivas quando o sistema de mobilidade urbana favorece o seu uso adequadamente. Conquanto, a ação pedalar compreende numerosos fatores, entre eles, podem-se destacar fatores sociais, econômicos e políticos.
No atual cenário da mobilidade urbana brasileira, as políticas nessa área não priorizam o uso de transporte ativo e de transporte público urbano. Ademais, a cultura automobilística ainda é muito forte na sociedade. Aragão e Souza (2016, p. 80) acreditam que há um desgaste social nas políticas voltadas para a mobilidade, devido à priorização do uso do veículo motorizado individual.

Apesar das suas claras vantagens, a bicicleta é associada muitas vezes a uma mobilidade típica da classe trabalhadora, como é comumente vista também no município de Campos dos Goytacazes. Entretanto, atualmente, diversos grupos da sociedade têm levantado questões pertinentes à mobilidade nas cidades, especialmente sobre o transporte ativo que, aos poucos, vai ganhando espaço nas discussões. Para Andrade et al. (2016, p. 13), é primordial reconhecer que parte dos conhecimentos efetivados sobre esse tipo de transporte no Brasil é devido à luta pela mobilidade por bicicleta que muitas organizações sociais têm enfrentado.

M E S T R A D 0

PESQUISA OPERACIONAL E INTELIGÊNCIA COMPUTACIONAL

\section{LINHA DE PESQUISA EM SAÚDE}


Resultados preliminares: da mobilidade urbana no Brasil aos desafios para a cidade de Campos dos Goytacazes/RJ

Os resultados iniciais apresentados neste artigo advêm de pesquisa bibliográfica, documental e de observações de campo. É importante ressaltar que fazem parte de uma pesquisa mais ampla', que está sendo desenvolvida com o objetivo de analisar as condições (potencialidades e desafios) do uso da bicicleta na cidade, considerando o debate sobre o transporte ativo como um agente promotor do desenvolvimento urbano sustentável. A proposta é avaliar essas condições do ponto de vista da estrutura urbana, das políticas públicas e das ações em torno da mobilidade, assim como a partir do olhar dos sujeitos que transitam e utilizam a bicicleta para realizar os deslocamentos cotidianos, aplicando tal estudo na cidade de Campos dos Goytacazes/RJ.

Entretanto, para o desenvolvimento desse estudo, também é de suma importância uma tarefa inicial de contextualizar os desafios da mobilidade urbana no Brasil em período recente, inclusive para avaliar as potencialidades do uso da bicicleta nas cidades, em especial, no caso da cidade de Campos. Sendo assim, uma retomada da política urbana e das ações em torno da mobilidade nos últimos anos é fundamental.

0 Ministério das Cidades, criado em 2003, possuía sua estrutura apoiada em três problemas sociais que mais atingiam as populações urbanas - a moradia, o saneamento ambiental e o transporte (mobilidade e trânsito). Para Maricato (2006, p. 214), a proposta do ministério era ocupar um vazio institucional, que fazia com que o governo federal se ausentasse da discussão sobre política urbana e o destino das cidades.

De acordo com Maricato (2006, p. 215), o ministério possui sua criação ligada ao movimento social urbano, que se iniciou ainda nos anos 1970 e que ganhou força nas duas décadas seguintes através da luta pela democratização do País e da reforma urbana. No entanto,

$1 \quad$ Esta pesquisa está sendo desenvolvida pelo primeiro autor no projeto de dissertação de mestrado intitulado "Potencialidades e desafios do uso da bicicleta no contexto da mobilidade urbana em Campos dos Goytacazes/RJ", sob a orientação da coautora, no âmbito do Programa de Pós-graduação em Desenvolvimento Regional, Ambiente e Políticas Públicas (PPGDAP/ UFF), com apoio da CAPES. com a entrada de novas bases no governo, em $1^{\circ}$ de janeiro de 2019, o Ministério das Cidades e o Ministério da Integração Nacional foram fundidos e transformados em Ministério do Desenvolvimento Regional.

A extinção do Ministério das Cidades pode trazer certa fragilidade em alguns temas específicos do debate acerca das políticas das cidades. No que tange à mobilidade urbana ${ }^{2}$, esta também pode ser afetada, embora, atualmente, esteja muito presente nas agendas de discussões de planejamento e desenvolvimento sustentável das cidades. Com o aumento do tráfego de veículos nas ruas a cada ano, os gestores públicos precisaram adotar nas suas políticas medidas e diretrizes que considerassem os diferentes modais como alternativas de deslocamento na cidade.

Apesar do contexto incerto em relação à política urbana e ao desenvolvimento regional no Brasil, a Lei ${ }^{0}$ $12.587 / 12$, denominada Lei da Mobilidade Urbana, instituiu aos municípios as atribuições de planejar e executar as políticas de mobilidade em seus territórios. Ademais, as cidades com mais de 20 mil habitantes ${ }^{3}$, além de outros fatores, são obrigadas a elaborar um plano de mobilidade urbana com a finalidade de promover o crescimento das urbes de forma ordenada.

Conforme se lê no documento da Lei $n^{0} 12.587 / 12$, compreende-se que a finalidade da Política Nacional de Mobilidade Urbana (PNMU) é:

\begin{abstract}
Art. $2^{\circ}$ A Política Nacional de Mobilidade Urbana tem por objetivo contribuir para 0 acesso universal à cidade, o fomento e a concretização das condições que contribuam para a efetivação dos princípios, objetivos e diretrizes da política de desenvolvimento urbano, por meio do planejamento e da gestão democrática do Sistema Nacional de Mobilidade Urbana (BRASIL, 2012).
\end{abstract}

0 crescimento desordenado das cidades colabora com um sistema defasado de transportes e deslocamentos. 0 processo de evolução em busca de

2 De acordo com 0 art. $3^{\circ}$, o Sistema de Mobilidade Urbana é "[...] o conjunto organizado e coordenado dos modos de transporte, de serviços e de infraestruturas que garante os deslocamentos de pessoas e cargas no território do Município" - (BRASIL, 2012).

30 Estatuto da Cidade estabelece que municípios com mais de quinhentos mil habitantes devem elaborar um plano de transporte urbano integrado, compatível com o plano diretor ou nele inserido (BRASIL, 2001, Art. 41. $\S 2^{\circ}$ ). 
um desenvolvimento requer um planejamento prévio da mobilidade urbana para que talvez se alcancem os princípios e as diretrizes da PNMU.

A política de mobilidade presente nas cidades brasileiras, na maioria das vezes, foi fundamentada e promovida para o transporte individual motorizado. Contudo, pode-se observar que existe uma preocupação por parte do poder público e de determinados grupos da sociedade civil com a questão apresentada. Para o Ministério das Cidades (2007a), o processo de transformação das cidades, de forma positiva, pode ser promovido a partir de relações de diferentes atores e processos na cidade

0 planejamento urbano, as políticas públicas e a sociedade em geral são elementos fundamentais a serem mobilizados para gerar interferências positivas na implementação dos processos de transformação das cidades. Cada vez mais deve estar presente a consciência coletiva em proporcionar lugar saudável para as gerações futuras (BRASIL, 2007a, p. 12).

Os modelos de Planejamento de Transportes foram substituídos pelos Planos de Mobilidade. Para o Ministério das Cidades (2007b, p. 15), à época, esta mudança se fazia necessária para que não ocorressem os mesmos erros cometidos nos planejamentos tradicionais, que muitas das vezes não saíam do papel. Os antigos planos, em sua maior parte, restringiam-se a propostas de intervenções na infraestrutura e da organização espacial dos serviços de transporte público.

As políticas públicas de mobilidade urbana são essenciais para um bom funcionamento do sistema de transporte. É notável que diversos atores da sociedade não têm acesso a esses serviços de maneira justa. Portanto, no processo de elaboração das políticas públicas de mobilidade, é coerente considerar qual modelo de cidade se pretende alcançar, uma cidade que continue privilegiando os transportes motorizados individuais ou uma cidade acessível e que promova um desenvolvimento sustentável. Para isso, é necessário garantir a implementação efetiva de novas políticas nessa área, para que não fiquem apenas no papel como os antigos casos de planejamento de transporte no Brasil.

Desde o final do século XIX, já se podia presenciar 0 aparecimento de ciclistas nas ruas. Com o passar dos anos, as cidades foram crescendo e, paralelo a esse fenômeno, a popularização do veículo motorizado individual. 0 cicloativismo (bicycle advocacy), movimento que defende o uso da bicicleta no planejamento urbano, é muito recente. Trigueiro $(2016$, p. 8) aponta que o discurso do movimento é muito bonito na prática, entretanto, as consequências para conseguir inserir a bicicleta no meio urbano foram drásticas, muitas das vezes, envolvendo acidentes com vítimas.

Em resposta a muitos movimentos, a reinvindicações, dados relevantes sobre uso do modal (bicicleta), muitos atores políticos têm adotado a ideia de que a bicicleta é um dos meios mais significativos para resolver o nó da imobilidade. (TRIGUEIRO, 2016, p. 8)

Para Xavier (2007, p. 123), a preocupação com o meio ambiente e a sustentabilidade do planeta tem feito com o que o cicloativismo cresça. As discussões em torno do andar e pedalar têm crescido como uma das soluções para o desenvolvimento sustentável e de cidades mais justas.

0 crescente movimento de cicloativistas, seja ele espontâneo, seja a partir de entidades formalizadas, como a União de Ciclistas do Brasil (UCB), tem contribuído para a promoção da bicicleta como transporte ativo no Brasil. Para Xavier et al. (2009), a presença dos movimentos, bem como das entidades acadêmicas, dos programas de cooperação internacional, entre outros atores, contribuiu para uma maior maturidade no que tange à Política por Mobilidade Cicloviária no Brasil.

Portanto, as cidades cresceram e se consolidaram não contemplando condições de mobilidade que garantissem um desenvolvimento justo e sustentável. No caso brasileiro, em que pese o esforço de políticas públicas recentes no sentido de pensar e rever 0 modelo de política urbana e de mobilidade adotados, os desafios ainda são consideráveis, uma vez que boa parte das ações estiveram restritas ao campo da legislação, sem impactos abrangentes e eficazes nas cidades.

Esses problemas atravessam não apenas as grandes cidades e os espaços metropolitanos, mas também as cidades fora dos grandes centros, que exercem funções de polarização regional, como as cidades médias, sendo um dos exemplos, Campos dos Goytacazes.

A cidade de Campos dos Goytacazes, situada na Região Norte Fluminense, apresenta algumas peculiaridades no que tange ao sistema de transporte urbano. Uma das precursoras no transporte inaugurou sua 
primeira linha férrea 14 anos após a primeira do Brasil, a de Mauá, em 1873. Em 1875, nas principais ruas da cidade, circulava o primeiro bonde para transporte de passageiros e, em meados do século $X X$, as primeiras linhas regulares de ônibus (SOUZA, 2014).

De acordo com Freire e Gualande Junior (2016, p. 56), desde que foi promulgado o Estatuto da Cidade, a participação de grupos que representem os usuários do transporte coletivo em Campos é um assunto evitado. Ainda, apesar do Conselho Municipal de Transporte ter sido promulgado em 2014, o aparelho é considerado ineficaz e ineficiente por alguns operadores do transporte, uma vez que não proporciona ações concretas perceptíveis de intervenção.

Atualmente, o sistema alimentador de transportes urbanos do município passa por uma atualização. A prefeitura está implantando o sistema do bilhete único. Segundo dados da Prefeitura Municipal de Campos dos Goytacazes (s/d), o sistema terá 235 vans e 60 micro-ônibus distribuídos em 60 linhas distritais. Vale ressaltar que as vans precisarão estar credenciadas junto ao Instituto Municipal de Trânsito e Transporte (IMTT) para poder circular. A proposta é que os ônibus circulem apenas no centro urbano da cidade, enquanto as vans e os micro-ônibus desloquem os passageiros dos distritos até o centro. 0 passageiro descerá em terminais estabelecidos pelo IMTT, trocando de veículo e pagando apenas uma passagem. Os usuários ainda podem acompanhar os horários por meio de um aplicativo para smartphone chamado Mobi Campos.

Campos dos Goytacazes, também conhecida como Planície Goitacá, apresenta, no centro urbano, um relevo favorável para o uso da bicicleta. Conquanto, o percurso cicloviário não é estruturado e não oferece nenhum suporte para os usuários, que acabam optando por outros meios de transporte, sendo a maioria o transporte individual motorizado. Ademais, ao analisar a malha cicloviária do município, percebe-se que é bem reduzida, não contemplando boa parte das áreas periféricas, comparando com a extensão do perímetro urbano da cidade (Figura 1).

Figura 1: Malha cicloviária de Campos dos Goytacazes.

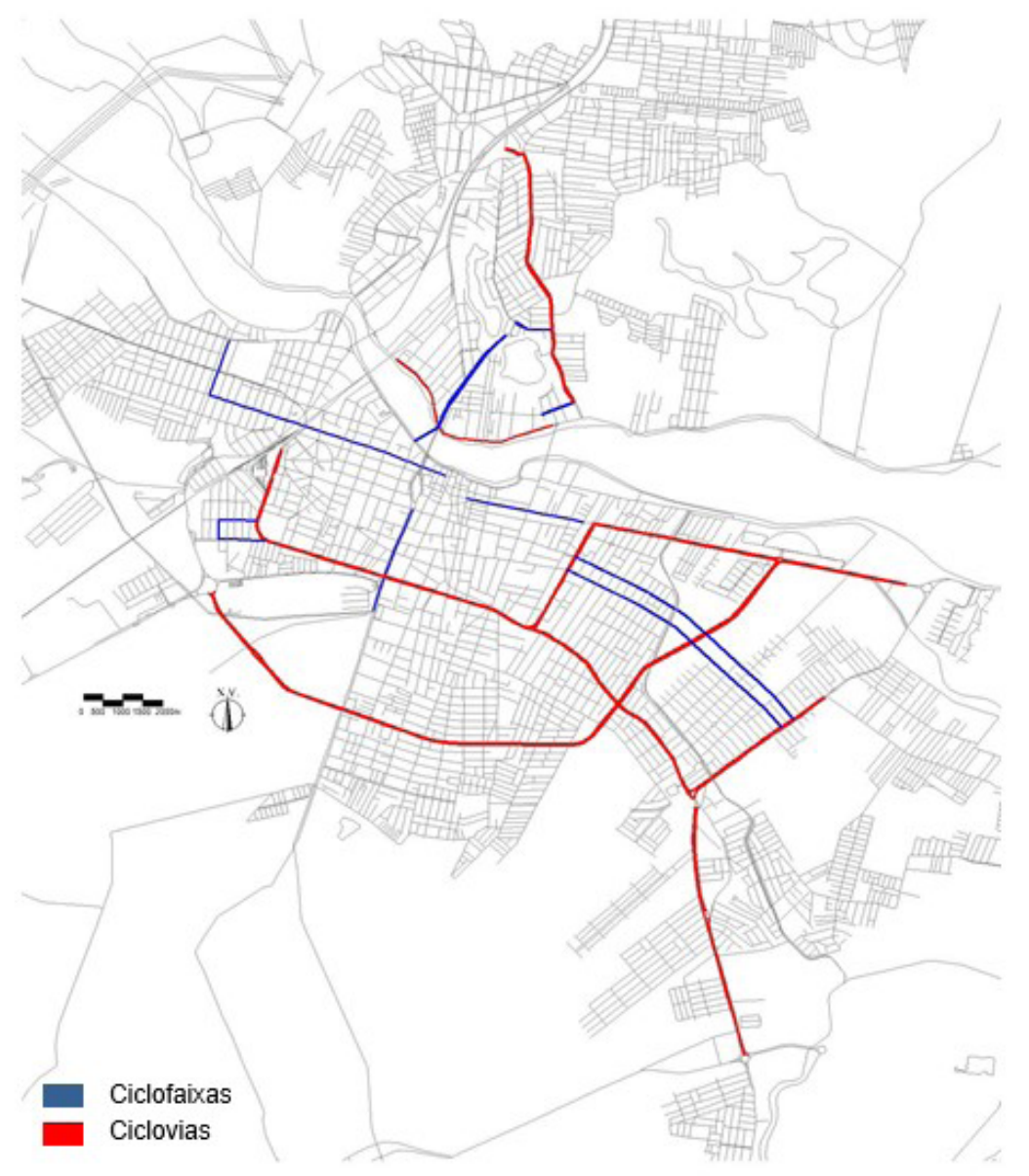

Fonte: VALE, 2018 - modificado pelo autor do trabalho, 2019. 
A Região Norte Fluminense passou por um período de implantação de grandes empreendimentos, como 0 Complexo Portuário do Açu, resultando em um crescimento populacional considerável. Muitas pessoas migraram para as áreas periféricas da cidade, onde grande parte dos conjuntos habitacionais se instalou. Este acréscimo também colabora com o aumento no número de veículos nas ruas, contribuindo diretamente com a emissão de gases do efeito estufa. Segundo Gehl (2013), o tráfego de bicicletas e pedestres utiliza menos recursos e afeta menos o meio ambiente do que qualquer outra forma de transporte. Os usuários fornecem a energia, e esta forma de transporte é barata, quase silenciosa e não poluente.

O Ministério das Cidades, em conjunto com a Secretaria de Mobilidade Urbana (SeMob), exigia que municípios acima de 20 mil habitantes apresentassem um plano de mobilidade urbana até meados de abril de 2019. No ano que o prazo final da entrega seria encerrado, o governo federal instituiu a MP $n^{0} 906$, prorrogando a data de apresentação do plano para 21 de abril de 2021. A partir desta nova data, os municípios que não atenderem às exigências não poderão receber os recursos do Orçamento Geral da União consignados à Secretaria Nacional de Mobilidade e Serviços Urbanos do Ministério do Desenvolvimento Regional (BRASIL, 2019).

Antes do novo adiamento concebido pelo governo federal, Campos ainda estava em fase de discussão do Plano de Mobilidade. Em 2019, ao acompanhar diversas audiências públicas e câmaras técnicas, notou-se que as questões debatidas acerca do plano ainda eram muito superficiais, além de boa parte das decisões não contemplarem grande parte da sociedade campista.
As audiências públicas, bem como as câmaras técnicas em que o debate central era o Plano de Mobilidade foram anunciadas às vésperas de serem realizadas. Os dias e horários marcados, em sua maioria, eram aqueles em que boa parte da população se encontra no trabalho e/ou escolas. Portanto, a participação da sociedade civil nas decisões foi muito baixa.

Um plano de mobilidade como este, em que o objetivo é alcançar toda a população, acaba possuindo algumas fragilidades, uma vez que muitos cidadãos campistas não expõem os desafios enfrentados ao circular pela cidade, sobretudo a classe trabalhadora que se desloca, grande parte, utilizando a bicicleta.

A cidade de Campos não possui nenhuma outra política pública exclusiva para o uso da bicicleta. A entrega do Plano de Mobilidade será um avanço importante na mobilidade urbana do município. Entretanto, além das fragilidades na comunicação das reuniões sobre o documento, a população não tem acesso ao texto prévio que discorre sobre todos os objetivos que se propõem a alcançar. Após todas as discussões e a elaboração de textos e mapas, o Plano de Mobilidade Sustentável de Campos aguarda a aprovação da Câmara Municipal.

O site Bicicleta nos Planos [2019], um dos maiores banco de dados dos Planos de Mobilidade do Brasil, acompanha o status das cidades e a entrega dos seus respectivos planos. A última atualização, em 30 de junho de 2019, demonstra que, de 470 cidades no País que deveriam apresentar o plano, 201 finalizaram, 135 estão em elaboração e 134 não possuem/ não se manifestaram.

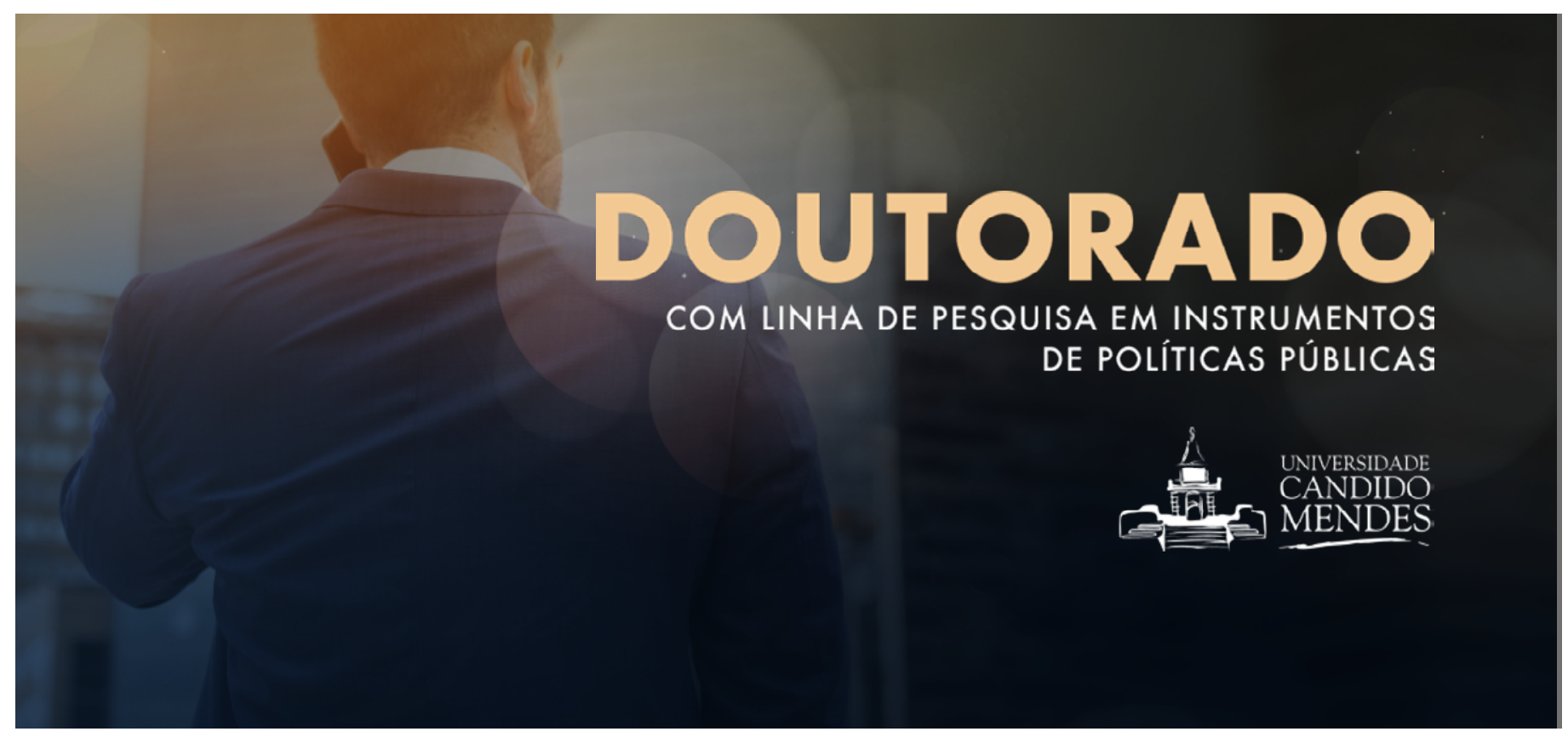


O Plano de Mobilidade Urbana Sustentável, assim nomeado pelo município de Campos dos Goytacazes, apresenta certa preocupação com o transporte ativo. Entretanto, faz-se necessário compreender essas e outras políticas públicas que abordem a mobilidade e investigar sua implementação, uma vez que, no Brasil, outros planos de planejamento de transporte não tiveram êxito, sendo uma das causas a priorização do automóvel nas ruas.

\section{Considerações finais}

Dessa forma, entende-se que as políticas e o contexto em que a mobilidade urbana se encontra no Brasil são indispensáveis ao se discutir as condições que o uso do transporte ativo, sobretudo a bicicleta, concorre nas cidades. Em Campos dos Goytacazes, não é diferente. 0 município, apesar do potencial que possui para estimular o uso da bicicleta, ainda apresenta desafios que precisariam ser enfrentados para o modal tornar-se um meio de transporte mais difundido e seguro. Tais desafios vão desde as políticas públicas até a infraestrutura cicloviária.

Como discutido no trabalho, a extinção do Ministério das Cidades pode provocar fragilidades na mobilidade urbana, uma vez que não existe mais uma pasta dedicada aos assuntos de trânsito e transporte. Diversos debates vinham trazendo questões relevantes para a promoção das cidades que valorizam o transporte ativo - caminhar e pedalar.

0 crescimento das cidades sem um planejamento contribuiu cada vez mais para o aumento de veículos motorizados nas ruas. A indústria automobilística expandiu-se, e os deslocamentos por meio do uso da bicicleta, bem como por transporte público, foram ficando em segundo plano. Em consequência desse grande investimento nas cidades que favoreçam o uso de automóveis, como o alargamento de vias e estacionamentos, a infraestrutura cicloviária foi ficando insuficiente para atender às demandas da população.

Em Campos, um reflexo disso são as desigualdades proporcionadas pela malha cicloviária do município. 0 percurso cicloviário da cidade não atende boa parte da população periférica, que necessita realizar deslocamentos maiores para acessar serviços e infraestru- tura básica. Ademais, as ciclovias e ciclofaixas são desconectas e não possuem uma continuidade, além de não existir integração do transporte público com diferentes modais.

Apesar das fragilidades no processo de elaboração do Plano de Mobilidade Urbana Sustentável de Campos, acredita-se que esta será uma política pública que poderá trazer benefícios para os usuários da bicicleta. Entretanto, é importante que haja convergência entre a legislação, os esforços de implementação por parte do poder público e a conscientização também da população, para que a política não fique apenas no papel, assim como na história do planejamento de transportes brasileiro.

0 trabalho parte de um estudo mais amplo, e pretendeu discutir a contextualização da mobilidade urbana no Brasil e em Campos dos Goytacazes. A pesquisa está em desenvolvimento, em fase de trabalho de campo, a fim de coletar dados mais específicos sobre as condições que a bicicleta encontra na cidade. 


\section{Referências}

ANDRADE, Vitor; RODRIGUES, Juciano Martins; MARINO, Filipe; LOBO, Zé. Apresentação - Produção de conhecimento para a promoção da mobilidade por bicicleta no Brasil: possibilidades e desafios. In: ANDRADE, Vitor; RODRIGUES, Juciano Martins; MARINO, Filipe; LOBO, Zé (orgs.) Mobilidade por bicicleta no Brasil. Rio de Janeiro: PROURB/UFRJ, 2016, p. 11-20.

ARAGÃO, Leonardo Andrade; SOUZA, Geraldo Alves de. Bicicleta em Manaus, AM: produção, usos e contradições. In: ANDRADE, Vitor; RODRIGUES, Juciano Martins; MARINO, Filipe; LOBO, Zé (orgs.). Mobilidade por bicicleta no Brasil. Rio de Janeiro: PROURB/UFRJ, 2016, p. 77-98.

BICICLETA NOS PLANOS. Como estão os Planmobs nas cidades do Brasil. [2019]. Disponível em: http://bicicletanosplanos.org/. Acesso em: 22 ago. 2019.

BRASIL. Lei $\mathbf{n}^{0} \mathbf{1 2 . 5 8 7}$, de 3 de janeiro de 2012. Institui as diretrizes da Política Nacional de Mobilidade Urbana; revoga dispositivos dos Decretos-Leis nos 3.326, de 3 de junho de 1941, e 5.405, de 13 de abril de 1943, da Consolidação das Leis do Trabalho (CLT), aprovada pelo Decreto-Lei no 5.452, de 10 de maio de 1943, e das Leis nos 5.917, de 10 de setembro de 1973, e 6.261, de 14 de novembro de 1975; e dá outras providências. Lei № 12.587, de 3 de Janeiro de 2012. Brasília, Disponível em: http://www.planalto.gov.br/ccivil_03/_ato2011-2014/2012/lei//12587.htm. Acesso em: 27 abr. 2019.

BRASIL. Lei $\mathbf{n}^{\mathbf{0}} \mathbf{1 0 . 2 5 7}$, de $\mathbf{1 0}$ de julho de 2001. Regulamenta os arts. 182 e 183 da Constituição Federal, estabelece diretrizes gerais da política urbana e dá outras providências. Lei № 10.257, de 10 de julho de 2011. Brasília, Disponível em: http://www.planalto.gov.br/ccivil_03/leis/leis_2001//10257.htm. Acesso em: 27 abr. 2019.

BRASIL. Medida Provisória $\mathbf{n}^{0}$ 906, de 19 de novembro de 2019. Altera a Lei $n^{0}$ 12.587, de 3 de janeiro de 2012, que institui as diretrizes da Política Nacional de Mobilidade Urbana. Disponível em: http://www.planalto.gov.br/ccivil_03/_ato2019-2022/2019/Mpv/mpv906.htm. Acesso em: 16 jan. 2020.

CRUZ, José Luis Vianna. Projetos nacionais, elites locais e regionalismo: desenvolvimento e dinâmica territorial no Norte Fluminense. 2003. Tese (Doutorado em Planejamento Urbano e Regional) - Universidade Federal do Rio de Janeiro, Rio de Janeiro, IPPUR-UFRJ, 2003.

MINISTÉRIO DAS CIDADES. Programa brasileiro de mobilidade por bicicleta - bicicleta Brasil. Caderno de referência para elaboração de Plano de Mobilidade por Bicicleta nas Cidades. Brasília: Secretaria Nacional de Transporte e da Mobilidade Urbana, 2007a. Disponível em: http://www.intt.gob. ve/repositorio/biblioteca/texto_relacionados/Livro_20Bicicleta_20Brasil.pdf. Acesso em: 24 abr. 2019.

MINISTÉRIO DAS CIDADES. PlanMob: Construindo a Cidade Sustentável. Caderno de referência para elaboração de Plano de Mobilidade Urbana. Brasília: Secretaria Nacional de Transporte e da Mobilidade Urbana, 2007b. Disponível em: https://www.mobilize.org.br/estudos/79/planmob--construindo-a-cidade-sustentavel.html. Acesso em: 24 abr. 2019.

FREIRE, Jussara; GUALANDE JUNIOR, Ailton. Tensões e conflitos no transporte coletivo de Campos dos Goytacazes: uma sociologia das filas de espera. Revista Brasileira de Sociologia da Emoção, [s.I.], v. 15, n. 45, p. 52-65, dez. 2016. Disponível em: http://www.cchla.ufpb.br/rbse/Freire\&JuniorArtDossie.pdf. Acesso em: 7 jul. 2019.

GEHL, Jan. Cidades Para Pessoas. Tradução Anita Di Marco. 2. ed. São Paulo: Perspectiva, 2013.

HARVEY, David. Cidades rebeldes: do direito à cidade à revolução urbana. Tradução Jeferson Camargo. São Paulo: Martins Fontes, 2014.

LEFEBVRE, Henri. A vida cotidiana no mundo moderno. São Paulo: Ática, 1991.

LEFEBVRE, Henri. A revolução urbana. Tradução de Sérgio Martins. Belo Horizonte: UFMG, 1999.

MARICATO, Ermínia. O Ministério das Cidades e a Política Nacional de Desenvolvimento Urbano. In: políticas sociais - acompanhamento e análise. Repositório Ipea, 12 fev. 2006, p. 211-220. Disponível em: http://repositorio.ipea.gov.br/bitstream/11058/4508/1/bps_n.12_ensaio2_ministerio12.pdf. Acesso em: 11 jul. 2019.

OLIVEIRA JÚNIOR, João Alencar. Direito à mobilidade urbana: a construção de um direito social. Revista dos Transportes Públicos: ANTP, São Paulo, ano 33, 2011. Disponível em: https://bicicletanarua.files.wordpress.com/2013/04/direito-a-mobilidade-urbana.pdf. Acesso em: 29 mai. 2019.

PREFEITURA MUNICIPAL DE CAMPOS DOS GOYTACAZES. Sistema alimentador do transporte: mais de 100 contratos assinados. Disponível em: https://www.campos.rj.gov.br/exibirNoticia.php?id_noticia=53688. Acesso em: 16 jul. 2019.

SOUZA, Horácio. História do $\mathbf{1}^{\circ}$ centenário da cidade de Campos 1835 - 1935. Campos dos Goytacazes, RJ: Essentia, 2014. 445 p. (Memórias Fluminenses; v.1). 
TRIGUEIRO, André. Prefácio. In: ANDRADE, Vitor; RODRIGUES, Juciano Martins; MARINO, Filipe; LOBO, Zé (orgs.). Mobilidade por bicicleta no Brasil. Rio de Janeiro: PROURB/UFRJ, 2016, p. 7-10.

VALE, Elias Andretti Dantas do. Pensar a bicicleta na cidade: proposta de intervenção no sistema cicloviário da Avenida 28 de Março em Campos dos Goytacazes/RJ. 2018. 110 f. Trabalho de conclusão de curso (Bacharelado em Arquitetura e Urbanismo) - Instituto Federal Fluminense, Campos dos Goytacazes, RJ, 2018. Disponível em: http://bd.centro.iff.edu.br/jspui/handle/123456789/1991. Acesso em: 20 abr. 2019.

VASCONCELLOS, Eduardo Alcântara de. Mobilidade urbana e cidadania. Rio de Janeiro: SENAC NACIONAL, 2012. 216 p.

XAVIER, Giselle Noceti Ammon. 0 cicloativismo no Brasil e a produção da lei de política nacional de mobilidade urbana. Em Tese: Revista Eletrônica dos Pós-Graduandos em Sociologia Política da UFSC, Florianópolis, v. 3 n. 2, p. 122-145, jan./jul. 2007.

XAVIER, Giselle Noceti Ammon; RAQUEL, Roberta; SOARES, André; GIUSTINA, Milton Della. A contribuição da sociedade civil para a inclusão da bicicleta no sistema de mobilidade urbana em Florianópolis/SC. In: CONGRESSO BRASILEIRO DE TRANSPORTE E TRÂNSITO DA ANTP, 17. 2009, Curitiba. Anais [...]. Curitiba, 2009. Disponível em: http://www.cefid.udesc.br/arquivos/id_submenu/1120/artigo_viaciclo_antp.pdf. Acesso em: 23 abri. 2019. 